\title{
The Child Survival Revolution
}

\author{
D. A. HENDERSON
}

The Johns Hopkins University, School of Hygiene and Public Health, Baltimore, Maryland 21205

The last century has witnessed profound, indeed dramatic, improvements in the health of children in the United States and other industrialized countries. Today, we know that of 100 children who are born in this country, 99 will celebrate their fifth birthday. Based on recent trends, there is every reason to believe that within the next decade, the mortality rate for those under five years will decrease again by half. Indeed, countries such as Finland and Sweden are already approaching such levels (11).

The death of a child in this country is becoming an uncommon event. This is in stark contrast to the situation in impoverished Third World countries where as many as 20 to $25 \%$ of those born do not celebrate their fifth birthday.

Many attribute these differences to our increased prosperity and improvements in education. Undoubtedly, these factors have been important, but many fail to appreciate that, at the turn of the century, standards of health in the United States were little different than the poorest of Third World countries today. In the United States in 1900, 18 of every 100 children did not live beyond 5 years; life expectancy was only 47 years; and 26 of our 96 largest cities had no sewerage system whatsoever (2). And yet, at the turn of the century, the United States was comparatively prosperous, with a per capita income equivalent to that of Hungary, Portugal, or Argentina today. And the U.S. census of 1900 revealed that nearly $90 \%$ of all adults were literate. Interest in the application of science to health, however, had not matured as witness the behavior of the Superintendent of the New York Hospital and then President of the American Hospital Association. That year, he declared: "I am absolutely at a loss for an understanding of the value of a medical library in a hospital" (2). Accordingly, he closed the library and gave away its books.

It is apparent that the transformation of health conditions in the United States had far more to do with application of science to health than to either prosperity or literacy, per se. Today, we are beginning to deal scientifically and practically with health conditions in the developing countries. The most important of these activities are presently embraced within a program called the "Child Survival Revolution" (3). It is a universal effort in which nations throughout the world are participating, joined by such disparate groups as the international and regional development banks and by Rotary International, which has pledged to raise $\$ 120$ million for the effort. Although much remains to be done, dramatic progress has already been made and more can be foreseen over the decade ahead. Surprisingly, however, the program and its achievements are, as yet, little-appreciated among professionals in this country. Thus, my presentation today is intended to describe briefly something of its genesis, its progress, and its rationale.

Preparatory to doing so, let me offer some data that illustrate measurements of change that have occurred over the past quarter century. First, let us compare traditional infant mortality rates in 1960 and 1986 (Table 1). In 1960, 45 of the 128 largest countries reported 150 or more deaths per 1000 births. Today, only eight report infant mortality rates of this magnitude. Note that as recently as 1900 in the United States infant mortality rates were in the range of 160 per 1000 births (4). Today this rate would be among the highest recorded.

Another measure for comparison, fostered by UNICEF, is the overall mortality rate of children under the age of five years (Table 2). Here, the progress is no less remarkable. Whereas 22 countries reported 300 deaths or more per 1000 births in 1960 , only one of the 128 countries records such a rate today. To be noted is the fact that 50 countries have rates below 50 , more than twice the number of countries recording such levels only 25 years ago. For comparison, the United States had a rate of 174 as recently as 1900 .

Life expectancy at birth, as you would expect, has increased dramatically (Table 3). For more than half the countries, it was less than 50 years in 1960. Today, nearly two-thirds of 131 countries record life expectancies of more than 60 years.

Fertility rates have also declined and although I should like to have portrayed these for you, I had difficulty obtaining 1960 data for many of the countries. A less satisfactory measure is the crude birth rate, i.e. births per 1000 population (Table 4). Here also there has been significant improvement.

Few recognize that the health experiences of our parents (or at least those of my generation) were comparable to those of many of the poorest developing countries today. Decades were required to effect significant change. In the developing countries, this time is being compressed. The developing world is not an unchanging morass of poverty, disease, and despair. Change is occurring. Much remains to be done, but there is hope.

An important contributor to this change is the Child Survival Revolution, which recognizes and incorporates the potential of simple, inexpensive interventions to prevent disease and death and to promote the well-being of children. No less important has been a growing appreciation by political leaders that improved health plays a vital role in national development, that healthy children offer a better hope for achieving their own and their country's aspirations. For you, the well-being of children has been your life, your preoccupation. But a new dimension has been added with a surge of national and international political will and commitment to bring this closer to fruition.

The genesis of the Child Survival Revolution has its origin in not one, but several, developments. To identify the most important helps to characterize it. An important component, and its foundation, is the objective of providing well-established vaccines against six of the major diseases to all of the world's childrenthe diseases being poliomyelitis, measles, tetanus, whooping cough, diphtheria, and tuberculosis $(5,6)$. This initiative followed inexorably from the experience gained in smallpox eradication.

The smallpox program, coordinated by WHO, succeeded in only a decade, and at a total cost of less than $\$ 8$ million per year in international support, in eliminating from the earth one of the most feared diseases known to man (7). Smallpox was a disease that, when the program began, annually claimed more than two million victims despite the fact that an effective vaccine had been known and available for more than a century and a half. However, an intensified program endorsed by the World Health Assembly eradicated the disease in only 10 years 9 months and 26 days. What accounted for this rapid change? First was the surprising discovery that, as recently as 1967 , most of the vaccine in use did not meet accepted standards. Some vaccine, in fact, was totally impotent. A WHO program requiring simply that all vaccine used in the program be of assured quality, as 
attested by international laboratories, made a profound difference. Second was the observation that, in most countries, trained health personnel were in surprisingly plentiful supply and that even with moderately effective supervision, they were capable of a remarkably high standard of performance and achievement. The numbers needed were really very small. In Africa, for example, most programs consisted of only 12 to 100 staff. Competent, motivated leaders, even though few in number, made the difference.

Third was the discovery that villagers, when properly approached, were usually willing, in fact eager, to cooperate in the program and sometimes even could serve as volunteer vaccinators. Fourth was the finding that a system for the routine notification and investigation of cases and outbreaks could be reasonably easily established and that the findings were invaluable in guiding strategy and in monitoring progress.

It seemed only logical to us that other vaccines might similarly be applied with good effect and, in the course of doing so, might serve to strengthen national health systems. Thus, as the smallpox eradication program was concluding, an Expanded Program of Immunization was launched. At that time, 1974, less than 5\% of all children in developing countries were receiving any of the vaccines that were in common use in the industrialized countries.

In retrospect, it is curious that so little effort has been made to provide vaccination, the single most cost-effective, most innocuous procedure in our entire medical armamentarium - and the simplest to administer. Quite simply, the efficacy of preventive as compared to curative procedures was not appreciated. Gradually, the immunization program gained momentum and, over recent years, progress has accelerated. Today, more than $50 \%$ of all children in the developing world are being vaccinated; vaccine demand has tripled in the past two years alone; poliomyelitis incidence in the Western Hemisphere has fallen to such low levels that an eradication program has begun with the objective of eliminating poliomyelitis from the hemisphere by the end of 1990 (8). The global objective is a vaccination program that reaches $90 \%$ of the world's children by 1990 . There is still a long way to go but the result, if successful, translates into the saving of more than three million lives.

A second and more recent development contributing to the Child Survival Revolution was the discovery that deaths from diarrhea could be sharply reduced with a simple oral rehydration solution comprised of salt and sugar. The first 1000000 packets

Table 1. Mortality rates for infants (under 1 y)-128 countries

\begin{tabular}{ccc}
\hline $\begin{array}{c}\text { No. of } \\
\text { deaths } / 1000 \\
\text { births }\end{array}$ & \multicolumn{2}{c}{ No. of countries* } \\
\cline { 2 - 3 }$\geq 200$ & 1960 & 1986 \\
$150-199$ & 9 & 0 \\
$100-149$ & 36 & 8 \\
$50-99$ & 31 & 31 \\
$25-49$ & 26 & 30 \\
$<25$ & 17 & 20 \\
\hline
\end{tabular}

* Unknown: Angola, Iran, Mozambique. Source: State of the World's Children, 1988.

Table 2. Mortality rates for children under $5 y-128$ countries

\begin{tabular}{ccc}
\hline $\begin{array}{c}\text { No. of } \\
\text { deaths } / 1000\end{array}$ & \multicolumn{2}{c}{ No. of countries* } \\
\cline { 2 - 3 } births & 1960 & 1986 \\
\hline 2300 & 22 & 1 \\
$200-299$ & 46 & 20 \\
$100-199$ & 25 & 36 \\
$50-99$ & 15 & 21 \\
$<50$ & 20 & 50 \\
\hline
\end{tabular}

* Unknown: Angola, Iran, Mozambique. Source: State of the World's Children, 1988.
Table 3. Life expectancy at birth-131 countries*

\begin{tabular}{ccc}
\hline & \multicolumn{2}{c}{ No. of countries } \\
\cline { 2 - 3 } No. of y & 1960 & 1986 \\
\hline$<40$ & 25 & 2 \\
$40-49$ & 43 & 22 \\
$50-59$ & 18 & 29 \\
$60-69$ & 29 & 33 \\
$70+$ & 16 & 45 \\
\hline
\end{tabular}

* Source: State of the World's Children, 1988.

Table 4. Crude birth rate*

\begin{tabular}{ccc}
\hline & \multicolumn{2}{c}{ No. of countries } \\
\cline { 2 - 3 } Births/1000 population & 1960 & 1986 \\
\hline $50+$ & 22 & 11 \\
$40-49$ & 67 & 43 \\
$30-39$ & 10 & 22 \\
$20-29$ & 15 & 22 \\
$10-19$ & 17 & 33 \\
\hline
\end{tabular}

* Source: State of the World's Children, 1988.

were purchased by UNICEF in 1975 and the supply lasted 18 months. Today, more than 1000000 packets are used daily (9). National programs have begun in more than 100 countries and in countries as diverse as Egypt, the Philippines, and Honduras, diarrheal disease mortality has decreased by $50 \%$. Indeed, pediatricians, even in this country, are finding that effective oral rehydration, provided early, diminishes the need for hospitalization and i.v. therapy.

A third and more recent development, an intervention that has only begun to be exploited, is based on the recent discovery by Sommer et al. (10) that the administration of vitamin A once every 6 months resulted in a dramatic decrease in childhood deaths in Indonesia, deaths due primarily to respiratory disease and diarrhea. Sommer's team administered vitamin A in standard UNICEF capsules containing 200000 IU to 1- to 6-year-old children in one group of villages; a second group of villages served as a control. Death rates among children in the treated villages were $34 \%$ less than those serving as controls. From other studies, it became apparent that vitamin A was vital for the maintenance of the integrity of surface epithelium and to humoral and cell-mediated immunity, effects that are compromised even among those who are marginally deficient. Vitamin A, previously given for the prevention of xexophthalmia, has now been accepted by WHO and UNICEF for widespread use throughout all developing countries that record case-fatality rates of $1 \%$ or more among children experiencing measles-a surrogate measure for vitamin A deficiency.

However significant these changes have been, more is promised. Just over the horizon is a whole gamut of new and improved vaccines. Indeed, there are few important diseases for which vaccines are not now moving through the development process. With the new techniques available to contemporary biomedical science, the time required for vaccine development has been greatly abbreviated. In the field of nutrition, one may speculate, as well, that there may be other micronutrients in addition to vitamin A that may be marginally deficient but as important to health.

It is not surprising that the global community has been captivated by these developments. In consequence, increased funds for health programs have been made available and the commitment of politicians is greater than it has ever been. Note, however, that each of these new initiatives is less than a decade old.

It is characteristic of revolutions, however, that in the excitement of the moment, critical deficits are often overlooked that potentially could frustrate the achievement of their full potential. This is no less the case with the Child Survival Revolution. I 
perceive three areas of special importance in which a special interest must be taken.

The first problem is that of institutionalizing systems for programs that are based in community involvement and community-wide action-and that can be sustained month after month and year after year. Many programs have so far relied on large-scale, intensive, short-term campaigns and, in doing so, they have awakened community interest and involvement in villages and households throughout entire areas and countries. But can such programs be sustained? In some areas, they appear to be successfully doing so but there has been little experience, as yet, over large areas. The leadership, support, and imagination of professionals such as yourselves will be vital if they are to succeed everywhere. The program is too important to be relegated solely to professional managers and professional politicians. We need trained pediatricians and public health leaders. The processes of change and adaptation must be continuing ones. Cases of vaccine-preventable diseases and nutritional illnesses need to be reported and investigated and epidemiological patterns discerned if they are to be controlled effectively.

The second area of need is for an ongoing, far-reaching program of research. To program managers, such a plea is too often labeled as the irrelevant cry of academics concerned more about their own careers than "getting on with the task." Let us not forget, however, that those once engaged in malaria eradication viewed that problem as entirely an administrative one-to apply DDT to the walls of houses. Deliberately, research programs were terminated. A decade later, with a global program foundering, there were no alternatives available and no research laboratories to take up the task. Politicians argued similarly when the global smallpox eradication program began. As they saw it, a good vaccine was available. The only problem was an administrative one-to apply it in the field. We resisted this view and promoted research throughout the program. By the time it concluded, little was the same as it had been-vaccine production methods had improved, new vaccinating devices were in universal use, our understanding of the epidemiology of smallpox had greatly changed, and the strategy and tactics substantially altered. Indeed, without research, smallpox would still be with us.

In the Child Survival Revolution, a number of simple, costeffective measures are now being widely applied. This effort must continue but, at the same time, we need to seek constantly for simpler, more effective tools and for better means for applying them. For example, none of the vaccines now in use is fully satisfactory. All could be improved. Meanwhile, candidate vaccines are beginning to emerge from the laboratory, but little support is yet being provided for testing them in the field, for the development of simpler preparations for administration, for the evaluation of different types of programs, or for the application of surveillance systems to monitor progress. Nutritional research in the developing countries is almost nonexistent. As has been the history with new programs, there is complacency, even overconfidence, that the tools are now available and that the only need is to apply them.
Finally and most importantly, we must continue to bear in mind that our ultimate goal is for each newborn to realize the potential inherent within him at birth. To assure healthy children but to fail to educate them or provide an economy that employs them is the ultimate exercise in futility. Although these problems are in large measure the province of educators and the business community, the numbers of children to be educated and employed is a critical part of the equation and this must be of concern to us. Child spacing and breastfeeding themselves contribute directly to the health of the child. Family planning services are still woefully inadequate; methods for contraception leave much to be desired; and support for these programs by some governments remains seriously deficient. Although a revolution in child survival is at hand, it would be futile indeed if we didn't at the same time address with vigor the question of numbers of children.

The potential for therapy and prevention is growing exponentially, nurtured by a magnificent base of biomedical research. You know it well-organ transplantation, fiber optics, nuclear imaging, recombinant DNA technology, and others. To the press, indeed to many of our colleagues, these developments appear to be the real challenges, the true frontiers of medicine. Indeed they are, but there are other frontiers, other challenges, sometimes less newsworthy but far more dramatic and urgent if we, as a species, are to achieve equilibrium with planet earth. The cutting edge to that problem is wanted children who are given the opportunity to grow in health to adulthood. The responsibility for achieving this cannot be relegated to those without technological competence any more than business can afford to relegate its leadership to accountants and lawyers. Your leadership and your articulate voices are even more vital to its realization than they have been in the past 100 years.

\section{REFERENCES}

1. UNICEF 1988 The State of the World's Children. Oxford University Press, Oxford

2. Preston SH 1985 Resources, knowledge and child mortality: a comparison of the U.S. in the late nineteenth century and developing countries today. In: International Population Conference, Vol 4 International Union for the Scientific Study of Population, Florence, pp 373-386

3. UNICEF 1983 The State of the World's Children, Oxford University Press, New York

4. Last JM, Foege WH 1986 International health. In: Last JM (ed) Public Health and Preventive Medicine. Appleton-Century-Crofts, Norwalk, CT pp 17931807

5. Henderson RH 1984 Vaccine preventable diseases of children: the problem. In: Protecting the World's Children: Vaccines and Immunization. Rockefeller Foundation, New York, pp 1-16

6. Henderson RH 1984 Providing immunization: the state of the art. In: Protecting the World's Children: Vaccines and Immunization. Rockefeller Foundation, New York, pp 17-38

7. Fenner F, Henderson DA, Arita I, Jezek Z, Ladnyi ID 1988 Smallpox and Its Eradication. World Health Organization, Geneva

8. World Health Organization 1987 Report of the Expanded Programme on Immunization. A report to the Global Advisory Group. World Health Organization, Geneva

9. World Health Organization 1988 Sixth programme report 1986-1987. World Health Organization, Geneva

10. Sommer A, Tarwotjo I, Djunaedi E, West K, Loeden A, Tilden R, Mele L, the Ache Study Group 1986 Impact of vitamin A supplementation on childhood mortality: a randomized controlled community trial. Lancet 1:1169-1173 